\title{
Quantitative Assessment of Airway Pathology in Subjects With COPD Using Low-Dose High-Resolution Computed Tomography
}

\author{
Huai Chen MD, Gai-qun Chen, Qing-si Zeng, Ting-ting Xia MM, Jia-xuan Zhou MM, and \\ Shi-jun Qiu MD
}

\begin{abstract}
BACKGROUND: The purpose of this study was to correlate airway parameters of COPD determined by low-dose high-resolution computed tomography (HRCT) with pulmonary function testing (PFT) results. METHODS: PFT data were collected for subjects with COPD and healthy controls. All subjects received inspiratory and expiratory phase low-dose HRCT. Bronchi in the apical segment of the right upper lobe (RB1), posterior segment of the right lower lobe (RB6), and lower lingual segment of the left upper lobe (LB5) were the target bronchi. Software automatically calculated airway wall area, inner area, and airway wall area percentage (percentage wall area for bronchial external area). RESULTS: A total of 75 COPD and 20 control subjects were included. The subjects with COPD were classified according to COPD stage, with 20 grade I, II, and III subjects, respectively, and $\mathbf{1 5}$ grade IV subjects. In COPD grade II, residual volume/total lung capacity was negatively correlated with airway wall area in LB5 $(r=-0.51)$. In COPD grade III, FVC was negatively correlated with airway wall area percentage in $\mathrm{LB5}(\mathrm{r}=-0.49)$ but positively correlated with airway wall area in $\mathrm{RB6}(\mathrm{r}=0.52)$; percent-of-predicted $\mathrm{FEV}_{1}$ was negatively correlated with airway wall area percentage in $\mathrm{RB1}(\mathrm{r}=-0.49)$; residual volume was negatively correlated with airway wall area $(r=-0.47)$, and total lung capacity was negatively correlated with airway wall area in RB1 ( $\mathrm{r}=\mathbf{- 0 . 5 2 )}$ (all, $P<.001)$. CONCLUSIONS: The results of this study suggest that airway parameters in different COPD grades have no uniform tendency of correlation with PFT, but some HRCT parameters are correlated to some PFT parameters. Key words: COPD; emphysema; HRCT; lung. [Respir Care 2017;62(7):953-962. (C) 2017 Daedalus Enterprises]
\end{abstract}

\section{Introduction}

COPD can be simply defined as partial air-flow limitation. However, COPD is in fact a complex systemic dis-

\footnotetext{
Drs Chen and Qiu are affiliated with the Medical Imaging Center, Nanfang Hospital, Southern Medical University, Guangzhou, China. Mr Chen is affiliated with Chaozhou Health School, Guangdong, China. Mr Zeng, Mr Xia, and Mr Zhou are affiliated with the Department of Radiology, First Affiliated Hospital of Guangzhou Medical University, Guangdong, China.
}

This study was supported by Science and Technology Planning Project of Guangdong Province, China (Grant 2014A020212608) and Public Science and Technology Research Funds Projects of NHFPC of the People's Republic of China (Grant 201402013). The authors have disclosed no conflicts of interest.

Supplementary material related to this paper is available at http:// www.rcjournal.com. ease and chiefly consists of chronic bronchitis and emphysema. ${ }^{1,2}$ Although small-airway pathology and emphysema can induce air-flow obstruction in patients with COPD, small-airway pathology is the most important factor. Micro-computed tomography $(\mathrm{CT})$ studies have shown that the diameter of terminal bronchioles in subjects with severe COPD is 100 times smaller than that of normal healthy controls, and this is before the occurrence of emphysema. ${ }^{3,4}$ Another study ${ }^{5}$ has shown that airway wall thickness in subjects with COPD is related to external airway diameter. As COPD develops, large and small airways both undergo

\footnotetext{
Correspondence: Shi-jun Qiu MD, Medical Imaging Center, Nanfang Hospital, Southern Medical University, No. 1838, Guangzhou Dadaobei Road, Baiyun District, Guangzhou City, Guangdong Province 510515, China. E-mail: shijunqiu1963@163.com.
}

DOI: $10.4187 /$ respcare.05186 
reconfiguration, thickening of airway walls, narrowing of airway lumen, and airway fibrosis after inflammation. Airway remodeling in subjects with COPD is the chief factor inducing air-flow obstruction. ${ }^{6}$

At present, although pulmonary function testing (PFT) is still the accepted standard for the confirmation and clinical grading of COPD, the results can be affected by a patient's age and other health factors, and PFT is associated with a relatively large margin of error. ${ }^{7}$ Furthermore, PFT may be normal in some patients in whom there are already abnormalities in small-airway function (diameter $<2 \mathrm{~mm}$ ), especially in the early stage of the disease. ${ }^{8,9}$

High-resolution computed tomography (HRCT) allows the assessment of airways as small as $1 \mathrm{~mm}$ in diameter and is useful for examining changes of lung tissue and airways in pulmonary diseases, including asthma and COPD. ${ }^{10,11} \mathrm{CT}$ is also useful for volume measurements, examination of tracheal morphology, quantification of emphysema, and analysis of perfusion in patients with COPD. ${ }^{12-15}$ A number of studies have sought to compare CT data, such as airway diameter and airway wall thickness, in subjects with and without lung disease (asthma, COPD, emphysema) and to correlate these parameters with disease severity. ${ }^{16-20}$ Much of the prior research, however, has consisted of quantitative studies of emphysema in subjects with COPD..$^{7,21-23}$ The purpose of this study was to correlate airway parameters of subjects with COPD determined by low-dose HRCT with PFT to determine the feasibility of using CT to determine the severity of COPD.

\section{Methods}

\section{Subjects}

This study recruited subjects with COPD seen at the First Affiliated Hospital of Guangzhou Medical University (Guangzhou Respiratory Disease Research Institute). The study was approved by the institutional review board of the hospital, and all subjects provided written informed consent.

Subjects were eligible for inclusion if they met the 2007 Global Initiative for Chronic Obstructive Lung Disease (GOLD) diagnostic standards. ${ }^{24}$ Briefly, the standards consist of evident chronic coughing, expectoration, $\mathrm{FEV}_{1} / \mathrm{FVC}<.70$, and $\mathrm{FEV}_{1}<80 \%$ of predicted value after inhaling a bronchodilator; no cough or expectoration, $\mathrm{FEV}_{1} / \mathrm{FVC}<.70$, and $\mathrm{FEV}_{1} \geq 80 \%$ of predicted value, and excluding other diseases; stable COPD (stable or mild symptoms of expectoration, coughing, and shortness of breath). Exclusion criteria included $\alpha 1$-antitrypsin deficiency, pneumonia, thoracic deformity, asthma, pulmonary fibrosis, lung cancer, tuberculosis, and history of thoracic surgery or other diseases that might affect pulmonary function. A normal control group consisted of

\section{QUICK LOOK}

\section{Current knowledge}

High-resolution computed tomography (HRCT) is useful for examining changes of lung tissue and airways in pulmonary diseases, including asthma and COPD. Much of the prior research, however, has consisted of quantitative studies of emphysema in subjects with COPD.

\section{What this paper contributes to our knowledge}

The results showed that the wall area of the apical segment of the right upper lobe of subjects with COPD was greater than that of control subjects. The apical segment of the right upper lobe, posterior segment of the right lower lobe, and lower lingual segment of the left upper lobe wall area proportions of subjects with COPD were uniformly greater than those of the control group, and the higher values in the apical segment of the right upper lobe and posterior segment of the right lower lobe were significant. The percentage of wall area was best able to reflect small-airway pathology.

subjects with normal PFT; no chronic coughing, expectoration, or shortness of breath; no evident respiratory pathologies before inclusion; no history of contact with dust or smoking history; no deformity of the chest profile caused by thoracic disease; and no other thoracic pathologies as determined by chest CT.

PFT and low-dose HRCT were performed within $3 \mathrm{~d}$ of each other. In all subjects, drugs that might affect the test results were suspended before testing because the subjects included in the study were considered stable. Before PFT and HRCT, subjects were administered $200 \mu \mathrm{g}$ of salbutamol sulfate by inhalation.

\section{Low-Dose HRCT}

A Toshiba Aquilion 16-slice spiral CT machine was used. Scanning was performed after subjects inhaled deeply and held their breath, and the scanning time was 6-8 $\mathrm{s}$. Scanning parameters were: tube voltage, $120 \mathrm{kV}$; tube current, $40 \mathrm{~mA}$; pitch, 16; $\mathrm{x}$-ray tube rotation velocity, 0.5 slice/rotation; field of view, $400 \mathrm{~mm} \times 400 \mathrm{~mm}$; acquisition array, $512 \times 512$; scanning acquisition thickness, $0.6 \mathrm{~mm}$; image reconstructed slice thickness, $1 \mathrm{~mm}$. A high-resolution reconstructive algorithm was used. Both inspiratory and expiratory studies were performed, but only inspiratory views were included in this study. This was because the airway was very constricted during the expiratory phase, especially due to collapse of the posterior wall, so the software could not accurately assess the con- 
dition of the airway during the expiratory phase. In addition, the majority of studies on this topic analyzed only the inspiratory phase, and expiratory views are primarily for visualizing the parenchyma.

\section{Data Analysis}

Vida Apollo 1.2 software developed by University of Iowa was employed for data analysis. After the collected DICOM data were entered into the computer system, the software automatically removed the mediastinum, major blood vessels, trachea, and tissue of the thoracic wall. This study opted to perform measurement of the apical segmental bronchus of the right upper lobe (RB1), posterior segmental bronchus of the right lower lobe (RB6), and lower lingual segmental bronchus of the left upper lobe (LB5) because these 3 bronchi have little variability and can reflect the overall condition of the airways of the lower lobes to a certain degree because of their location, although different approaches have been described.5,25 Lumen volume representation technology was used to perform post-processing of the images, and the software automatically generated CMPR images of the bronchial tree. In accordance with images of the bronchial trees, axial point array diagrams and virtual endoscopic images of the bronchi were used to track the route of the target bronchi. The target bronchi were located from different angles of rotation. Despite the fact that the planar scale was perpendicular to the long axis of the target bronchi, short-axis images were obtained of the target bronchi, measurements were made at a distance of $3 \mathrm{~mm}$ from the distal bronchial openings (Fig. 1), and the software automatically calculated the airway wall area, inner area, and airway wall area percentage. The mean values of these 3 measurements were calculated and used in the analysis.

\section{Pulmonary Function Testing}

A Quark PFT series (Cosmed, Rome, Italy) PFT instrument meeting American Thoracic Society/European Respiratory Society instrument quality control standards was used. After $10 \mathrm{~min}$, the subject was instructed to breathe calmly for 3-4 cycles and then, after deep inhalation, suddenly, continuously, and steadily exhale completely with maximum effort to completion via an interface device. After complete exhalation with no interruption or coughing, the patient inhaled completely with maximum effort. Requirements of an adequate test consisted of a peak expiratory flow that quickly appeared on the maximum expiratory flow-volume curve, extrapolated capacity $<5 \%$ FVC or $150 \mathrm{~mL}$, smooth expiratory phase descending curve, and time capacity curve displaying an expiratory phase platform and volume change of $<25 \mathrm{~mL} / \mathrm{s}$. At least 3 measurements were performed for $\mathrm{FEV}_{1}$, and FVC should
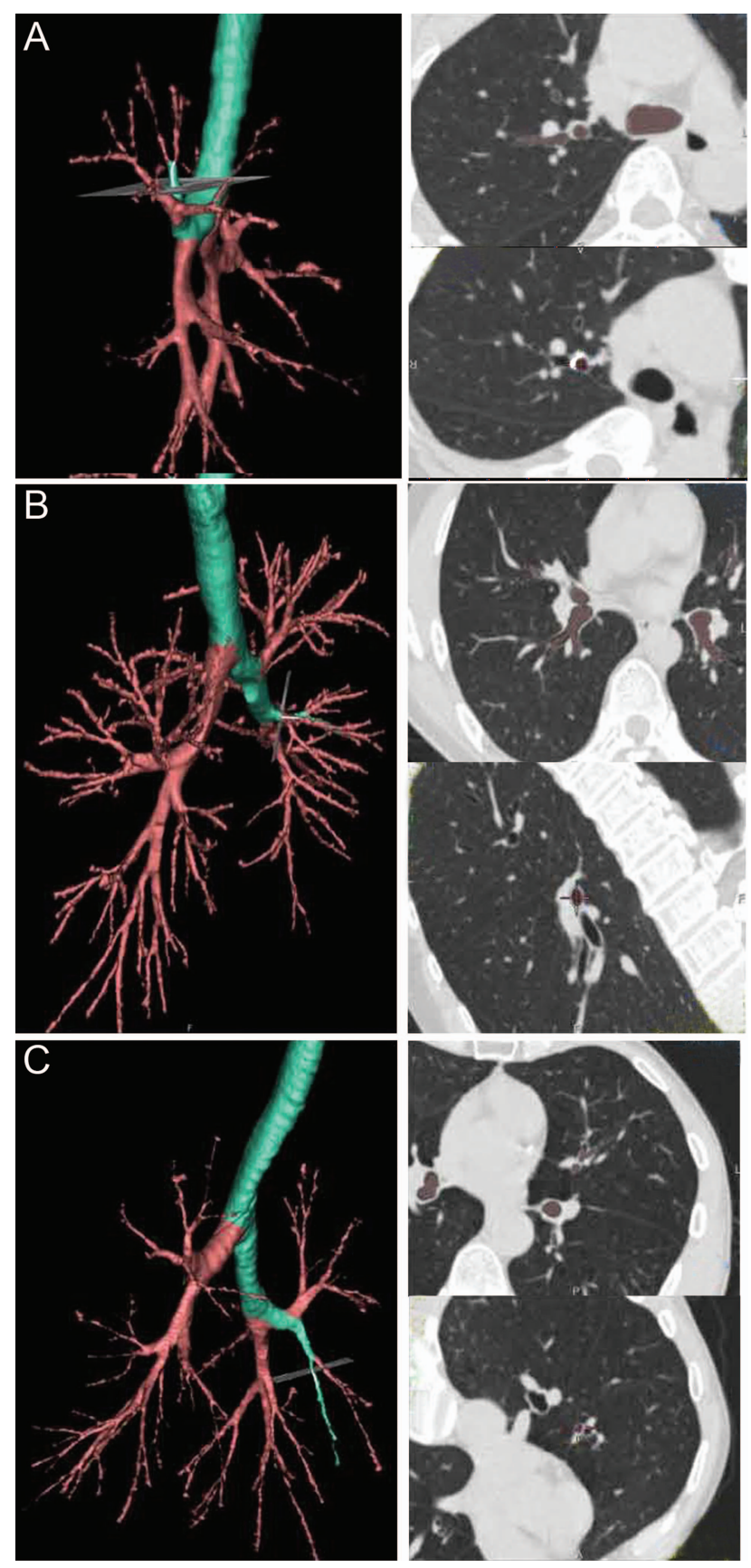

Fig. 1. Representative computed tomography images of the apical segmental bronchus of the right upper lobe $(A)$, posterior segmental bronchus of the right lower lobe (B), and lower lingual segmental bronchus of the left upper lobe (C). On the left are 3-dimensional reconstructions. Computed tomography images on the right show slices perpendicular to the bronchi being measured.

be $<150 \mathrm{~mL}$. The maximum $\mathrm{FVC}$ and $\mathrm{FEV}_{1}$ values were reported, and the best of the other values were taken as the maximum FVC $+\mathrm{FEV}_{1}$ and measurement value with a smooth curve. PFT values obtained included FVC, percent-of-predicted $\mathrm{FEV}_{1}, \mathrm{FEV}_{1} / \mathrm{FVC}$, residual volume (RV), and total lung capacity (TLC). TLC and RV were mea- 
sured using body plethysmography, and the RV/TLC was calculated.

\section{Statistical Analysis}

Subject demographic characteristics, lung function data, and bronchial size were summarized as mean $\pm \mathrm{SD}$ for continuous variables and $n(\%)$ for categorical variables. Differences among groups were compared using one-way analysis of variance with a post hoc pair-wise comparison. The Bonferroni test was used for continuous variables with normal distribution; the Kruskal-Wallis test was used with a post hoc pair-wise comparison, the Mann-Whitney U test was used for continuous variable without normal distribution; and the Pearson chi-square test was used for categorical variables. Two-way analysis of variance was also performed with a post hoc pair-wise comparison, the Bonferroni test, for continuous variables by considering some covariates (sex and body mass index [BMI]). A partial Pearson correlation analysis was performed to identify the correlation of lung function with bronchial size with adjustment for BMI and COPD grade, and a coefficient of correlation was reported. All statistical assessments were 2-tailed and considered significant at $P<.05$. An adjusted significance level of $.01(.05 / 5)$ was considered for the post hoc pair-wise comparisons. All statistical analyses were performed with IBM SPSS 22 for Windows (IBM Corp, Armonk, New York).

\section{Results}

A total of 75 subjects with COPD and 20 control subjects were included in the analysis, and demographic characteristics, lung function data, and bronchial sizes are summarized in Table 1. The subjects with COPD were classified into 4 groups according to COPD stage, with 20 grade I, II, and III subjects, respectively, and 15 grade IV subjects. The majority of the subjects with COPD were male, and the mean age of grade I, III, and IV subjects was greater than that of the control group (sex: $P<.001$ and $<.001$ for grade I and III subjects vs control group; age: all, $P<.001$ for grade I, III, and IV subjects vs control group). Lung function parameters were significantly different among the groups (all, $P<.001$, except for percent-ofpredicted TLC, $P=.03$ ).

Bronchial sizes were significantly different among the groups, except for the inner area and airway wall area in RB6 (RB1: $P<.001, P<.001$, and $P<.001$ for inner area, airway wall area, and airway wall area percentage, respectively; RB6: $P=.20, P=.48$, and $P<.001$ for inner area, airway wall area, and airway wall area percentage, respectively; LB5: $P<.001, P=.01$, and $P=.032$ for inner area, airway wall area, and airway wall area percentage, respectively). COPD grade IV subjects had lower inner area in RB1 and LB5 than grade I subjects $(P=.01$ in RB1 and $P<.001$ in LB5). COPD grade IV subjects had a lower airway wall area in RB1 than grade II subjects ( $P=.01$ in RB1). COPD grade IV subjects had a higher airway wall area percentage in RB1 and RB6 than control subjects (both, $P<.001$ in RB1 and RB6) and a higher airway wall area percentage in RB1 than grade I subjects $(P<.001)$ (see Table 1$)$.

The correlations of lung function with bronchial size adjusted for BMI and COPD grade are shown in Table 2. FVC was positively correlated with inner area in RB1, LB5, and RB6 $(\mathrm{r}=0.25,0.32$, and $0.33, P=.02, P<.001$, $P<.001$, respectively). FVC was also positively correlated with airway wall area in LB5 and RB6 ( $\mathrm{r}=0.26$ and $0.25, P=.01$ and $P=.02$, respectively). Percent-ofpredicted $\mathrm{FEV}_{1}$ was positively correlated with airway wall area in LB5 $(\mathrm{r}=0.22, P=.031)$, and $\mathrm{FEV}_{1} / \mathrm{FVC}$ was negatively correlated with airway wall area in RB6 $(\mathrm{r}=-0.24$, $P=.02) . \mathrm{RV}$ was negatively correlated with inner area in RB1 ( $\mathrm{r}=-0.21, P=.047)$. The RV/TLC was negatively correlated with inner area and airway wall area in RB1 ( $\mathrm{r}=-0.27$ and $-0.26, P=.01$ and $P=.01$, respectively). There was no significant correlation between TLC and bronchial size.

Correlation analysis between lung function and bronchial size was also performed with adjustment for BMI and COPD grade separately (Table 3 ). In the control group, FVC was positively correlated with inner area in LB5 ( $\mathrm{r}=0.47, P=.043), \mathrm{FEV}_{1} / \mathrm{FVC}$ was negatively correlated with airway wall area in RB6 $(\mathrm{r}=-0.59, P=.01)$, and TLC was positively correlated with airway wall area percentage in LB5 ( $\mathrm{r}=0.51, P=.03)$. In subjects with COPD grade I, there were no significant correlations. In subjects with COPD grade II, the RV/TLC was negatively correlated with airway wall area in LB5 $(\mathrm{r}=-0.51$, $P=.03$ ). In subjects with COPD grade III, FVC was negatively correlated with airway wall area percentage in LB5 ( $\mathrm{r}=-0.49, P=.033$ ) but positively correlated with airway wall area in RB6 ( $\mathrm{r}=0.52, P=.02)$; percentof-predicted $\mathrm{FEV}_{1}$ was negatively correlated with airway wall area percentage in RB1 ( $\mathrm{r}=-0.49, P=.035)$; $\mathrm{RV}$ was negatively correlated with airway wall area in $\mathrm{RB} 1(\mathrm{r}=-0.47$, $P=.040)$; and TLC was negatively correlated with airway wall area in RB1 $(\mathrm{r}=-0.52, P=.02)$.

Because the mean age of subjects with COPD grade I, III, and IV was greater than that of the control group, the correlation between bronchial size and lung function was analyzed with adjustment for age, BMI, and COPD grade (see supplementary Table 1 in the supplementary materials at http://www.rcjournal.com). The results were the same as those presented in Table 2, except for the correlation between airway wall area and FVC in RB6; however, the significance level was borderline $(P=.050)$. Also, considering the age effect, correlation between bronchial size 
Table 1. Demographic Characteristics, Lung Function, and Bronchial Size by COPD Grade

\begin{tabular}{|c|c|c|c|c|c|c|}
\hline Variables & $\begin{array}{l}\text { Control } \\
(n=20)\end{array}$ & $\begin{array}{l}\text { Grade I } \\
(n=20)\end{array}$ & $\begin{array}{l}\text { Grade II } \\
(n=20)\end{array}$ & $\begin{array}{l}\text { Grade III } \\
(n=20)\end{array}$ & $\begin{array}{l}\text { Grade IV } \\
(n=15)\end{array}$ & $P$ \\
\hline \multicolumn{7}{|l|}{ Demographic } \\
\hline Female/male sex, $n$ & $9 / 11$ & $0 / 20 \dagger$ & $3 / 17$ & $1 / 19 \dagger$ & $2 / 13$ & $<.001 *$ \\
\hline Age, mean \pm SD y & $57.9 \pm 4.5$ & $66.6 \pm 8.1 \dagger$ & $64.7 \pm 9.2$ & $66.9 \pm 7.5 \dagger$ & $64.3 \pm 3.8 \dagger$ & $<.001 *$ \\
\hline $\mathrm{BMI}$, mean $\pm \mathrm{SD} \mathrm{kg} / \mathrm{m}^{2}$ & $23.9 \pm 3.1$ & $22.2 \pm 2.1$ & $22.4 \pm 2.7$ & $22.0 \pm 4.0$ & $19.0 \pm 3.3$ & $.01 *$ \\
\hline Smoking history, $n(\%)$ & NA & $17(85)$ & $14(70)$ & $19(95)$ & $13(86.7)$ & .23 \\
\hline Smoking index, mean \pm SD pack-years & NA & $36.44 \pm 28.31$ & $28.16 \pm 28.52$ & $41.25 \pm 20.90$ & $44.12 \pm 18.82$ & .14 \\
\hline Exacerbations in recent 6 months, $n(\%)$ & & & & & & ND \\
\hline None & NA & $10(50)$ & $10(50)$ & $3(15)$ & $3(20)$ & \\
\hline 1 & NA & $10(50)$ & $8(40)$ & $14(70)$ & $7(46.7)$ & \\
\hline 2 & NA & $0(0)$ & $1(5)$ & $1(5.0)$ & $3(20)$ & \\
\hline 3 & NA & $0(0)$ & $0(0)$ & $2(105)$ & $1(6.7)$ & \\
\hline 4 & NA & $0(0)$ & $0(0)$ & $0(0)$ & $1(6.7)$ & \\
\hline 5 & NA & $0(0)$ & $1(5)$ & $0(0)$ & $0(0)$ & \\
\hline \multicolumn{7}{|l|}{ Lung function } \\
\hline $\mathrm{FVC}$, mean $\pm \mathrm{SD} \mathrm{L} / \mathrm{s}$ & $103.6 \pm 12.8$ & $109.1 \pm 8.9$ & $89.3 \pm 9.8 \dagger+$ & $78.6 \pm 10.8 \dagger \ddagger$ & $61.6 \pm 7.0 \dagger \div \S \llbracket$ & $<.001 *$ \\
\hline $\mathrm{FEV}_{1}$, mean $\pm \mathrm{SD} \%$ predicted & $101.2 \pm 12.4$ & $91.9 \pm 7.4 \dagger$ & $66.9 \pm 7.5 \dagger+$ & $42.1 \pm 4.5 \dagger \neq \S$ & $26.3 \pm 2.3+\uparrow \S \mathbb{I}$ & $<.001 *$ \\
\hline $\mathrm{FEV}_{1} / \mathrm{FVC}$, mean $\pm \mathrm{SD}$ & $0.81 \pm .06$ & $0.66 \pm 0.03 \dagger$ & $0.61 \pm 0.06 \dagger+$ & $0.43 \pm 0.06 \dagger+\S$ & $0.34 \pm 0.04 \dagger \div \S \mathbb{I}$ & $<.001^{*}$ \\
\hline $\mathrm{RV}$, mean $\pm \mathrm{SD} \%$ predicted & $111.9 \pm 23.2$ & $114.8 \pm 31.0$ & $118.8 \pm 23.4$ & $154.5 \pm 25.4 \dagger+\S$ & $176.5 \pm 37.1 \dagger \ddagger \S$ & $<.001 *$ \\
\hline $\mathrm{TLC}$, mean $\pm \mathrm{SD} \%$ predicted & $103.3 \pm 14.3$ & $103.7 \pm 11.5$ & $92.9 \pm 18.1$ & $105.9 \pm 14.2$ & $107.4 \pm 14.6$ & $.03 *$ \\
\hline $\mathrm{RV} / \mathrm{TLC}$, mean $\pm \mathrm{SD} \%$ predicted & $106.8 \pm 10.4$ & $108.2 \pm 18.0$ & $122.9 \pm 19.5$ & $150.1 \pm 12.0 \dagger \ddagger \S$ & $167.3 \pm 18.7 \dagger \div \S$ & $<.001^{*}$ \\
\hline \multicolumn{7}{|l|}{ Bronchial size, mean $\pm \mathrm{SD}$} \\
\hline \multicolumn{7}{|l|}{ RB1 } \\
\hline Inner area, $\mathrm{mm}^{2}$ & $17.7 \pm 5.5$ & $23.0 \pm 6.0$ & $22.4 \pm 7.7$ & $19.9 \pm 7.2$ & $15.1 \pm 5.6 \div$ & $<.001 *$ \\
\hline Airway wall area, $\mathrm{mm}^{2}$ & $30.3 \pm 7.0$ & $36.9 \pm 8.9$ & $38.8 \pm 9.3$ & $34.5 \pm 7.9$ & $29.3 \pm 6.9 \S$ & $<.001 *$ \\
\hline Airway wall area percentage & $61.8 \pm 3.7$ & $63.6 \pm 2.3$ & $64.6 \pm 3.6$ & $66.7 \pm 4.4 \dagger$ & $68.5 \pm 4.0 \dagger \dagger$ & $<.001 *$ \\
\hline \multicolumn{7}{|l|}{ RB6 } \\
\hline Inner area, $\mathrm{mm}^{2}$ & $22.48 \pm 6.58$ & $25.8 \pm 6.9$ & $23.9 \pm 5.1$ & $21.9 \pm 9.4$ & $18.9 \pm 4.4$ & .20 \\
\hline Airway wall area, $\mathrm{mm}^{2}$ & $33.5 \pm 8.8$ & $38.5 \pm 9.3$ & $39.8 \pm 7.4$ & $37.7 \pm 11.4$ & $34.9 \pm 6.8$ & .48 \\
\hline Airway wall area percentage & $61.2 \pm 4.4$ & $64.5 \pm 3.3$ & $65.7 \pm 2.1 \dagger$ & $66.4 \pm 5.5 \dagger$ & $68.3 \pm 4.3 \dagger$ & $<.001 *$ \\
\hline \multicolumn{7}{|l|}{ LB5 } \\
\hline Inner area, $\mathrm{mm}^{2}$ & $14.8 \pm 3.9$ & $19.0 \pm 5.6$ & $16.0 \pm 3.5$ & $14.3 \pm 3.6 \%$ & $11.6 \pm 2.4 \div$ & $<.001^{*}$ \\
\hline Airway wall area, $\mathrm{mm}^{2}$ & $26.7 \pm 6.8$ & $32.0 \pm 7.3$ & $29.3 \pm 6.3$ & $26.8 \pm 5.4$ & $23.8 \pm 4.4 \ddagger$ & $.01 *$ \\
\hline Airway wall area percentage & $62.5 \pm 4.8$ & $64.4 \pm 3.1$ & $64.5 \pm 4.0$ & $66.2 \pm 2.4$ & $67.9 \pm 3.8$ & $.032 *$ \\
\hline $\begin{array}{l}*, P<.05 ; \text { significant difference among given groups. } \dagger, \\
\text { BMI }=\text { body mass index } \\
\text { NA }=\text { not applicable } \\
\text { ND }=\text { not derived } \\
\text { RV }=\text { residual volume } \\
\text { TLC }=\text { predicted total lung capacity } \\
\text { RB1 }=\text { apical segment of the right upper lobe bronchi } \\
\text { RB } 6 \text { = posterior segment of the right lower lobe } \\
\text { LB5 }=\text { lower lingual segment of upper left lobe bronchi }\end{array}$ & $\S$, and $\mathbb{I}, P<.001$ & gnificant difference as & ompared with control ( & grade I ( $¥$ ), grade II (§) & nd grade III COPD (II). & \\
\hline
\end{tabular}

and lung function was analyzed with adjustment for age and BMI with respect to COPD grade (supplementary Table 2). In grade I COPD, an additional significant correlation was noted in RB1 (airway wall area percentage vs percent-of-predicted $\mathrm{RV}: \mathrm{r}=-0.51, P=.03)$. In grade II COPD, 2 additional significant correlations were noted in LB5 (inner area vs percent-of-predicted $\mathrm{FEV}_{1}: \mathrm{r}=0.53$, $P=.02$; airway wall area percentage vs percent-ofpredicted $\left.\mathrm{FEV}_{1}: \mathrm{r}=-0.48, P=.045\right)$. In addition, in grade III COPD, 2 correlations that were significant in the prior analysis became nonsignificant (RB1: airway wall area vs percent-of-predicted RV: $\mathrm{r}=-0.46, P=.056$; RB6: airway wall area vs FVC: $\mathrm{r}=0.47, P=.050)$.

Lung function was compared between smokers and nonsmokers, and the results showed that smokers had poorer lung function than nonsmokers, except for the ratio of percentage-of-predicted TLC (supplementary Table 3). We then performed a subgroup analysis for the correlation of lung function with bronchial size that considered the effect of smoking on lung function (ie, correlation analysis was performed for smokers and nonsmokers) (supplementary Table 4). The analysis showed that there was no signifi- 
Table 2. Correlation of Lung Function With Bronchial Size

\begin{tabular}{|c|c|c|c|c|c|c|}
\hline & FVC & $\mathrm{FEV}_{1}, \%$ Predicted & $\mathrm{FEV}_{1} / \mathrm{FVC}$ & RV, \% Predicted & TLC, $\%$ Predicted & RV/TLC, \% Predicted \\
\hline \multicolumn{7}{|l|}{ RB1 } \\
\hline Inner area & $0.252 *$ & 0.113 & 0 & $-0.206^{*}$ & -0.108 & $-0.274 * *$ \\
\hline Airway wall area & 0.176 & 0.13 & 0.036 & -0.174 & -0.061 & $-0.259^{*}$ \\
\hline Airway wall area percentage & 0.017 & -0.063 & 0.064 & -0.109 & -0.152 & 0.029 \\
\hline \multicolumn{7}{|l|}{ LB5 } \\
\hline Inner area & $0.317 * *$ & 0.189 & -0.018 & -0.147 & -0.121 & -0.167 \\
\hline Airway wall area & $0.261 *$ & $0.224 *$ & -0.057 & -0.104 & -0.076 & -0.188 \\
\hline Airway wall area percentage & 0.02 & 0.081 & -0.087 & 0.12 & 0.123 & -0.041 \\
\hline \multicolumn{7}{|l|}{ RB6 } \\
\hline Inner area & $0.328 * *$ & 0.131 & -0.082 & -0.103 & -0.011 & -0.168 \\
\hline Airway wall area & $0.252 *$ & 0.017 & $-0.238^{*}$ & -0.017 & 0.041 & -0.106 \\
\hline Airway wall area percentage & -0.128 & 0.013 & 0.064 & -0.022 & 0.01 & -0.125 \\
\hline $\begin{array}{l}\text { Data are presented as coefficient of correl } \\
\text { RV }=\text { residual volume } \\
\text { TLC }=\text { total lung capacity } \\
\text { RB1 }=\text { apical segment of the right upper } \\
\text { RB6 }=\text { posterior segment of the right low } \\
\text { LB5 }=\text { lower lingual segment of upper lef }\end{array}$ & $\begin{array}{l}\text { on with adjustme } \\
\text { e bronchi } \\
\text { lobe } \\
\text { obe bronchi }\end{array}$ & th for body mass index and C & PD grade. *, $P<$ & $05 ; * *, P<.001 ;$ significa & t correlation. & \\
\hline
\end{tabular}

cant correlation between lung function and bronchial size in RB1. In LB5 in nonsmokers, there was a significant correlation between inner area and $\mathrm{FVC}(\mathrm{r}=0.42, P=.02)$; inner area and percent-of-predicted RV $(\mathrm{r}=-0.39$, $P=.032)$; inner area and percent-of-predicted RV/TLC $(\mathrm{r}=-0.51, P<.01)$; airway wall area and percent-ofpredicted $\mathrm{FEV}_{1}(\mathrm{r}=0.39, P=.034)$; and airway wall area and percent-of-predicted RV/TLC $(\mathrm{r}=-0.48, P=.01)$. There was no significant correlation between lung function and bronchial size in smokers. In RB6, a significant correlation was found between inner area and FEV $(\mathrm{r}=0.28, P=.031)$ in smokers and between airway wall area and $\mathrm{FEV}_{1} / \mathrm{FVC}(\mathrm{r}=-0.488, P=.01)$ in non-smokers. Subgroup analysis with respect to COPD grade was not performed because the data were not suitable for subgroup analysis.

\section{Discussion}

This study measured parameters of the apical segmental bronchus of the right upper lobe (RB1), posterior segmental bronchus of the right lower lobe (RB6), and lower lingual segmental bronchus of the left upper lobe (LB5), which can reveal pathology of the large airways. The primary result was that the airway wall area percentage values of subjects with COPD were uniformly greater than those of healthy control subjects, and the airway wall area percentage values were greater than those in subjects with COPD grade I, II, and III disease. However, we must emphasize that statistical significance was not observed.

Pairwise comparisons of control group data and the data of subjects with different grades of COPD showed that although there was no statistically significant difference between some groups and although early subjects with COPD may have slightly enlarged airway lumens, the airway lumen was significantly smaller in grade III and grade IV subjects. In addition, whereas the airway wall area may be relatively large in grade I and II COPD, it begins to shrink by grade III and has shrunk significantly by grade IV. Airway wall area percentage gradually increases with the severity of COPD and is significantly increased in grade III and IV disease. These findings indicate that although airway lumen and airway wall area have both decreased by late-stage COPD, the decrease in airway lumen area tends to be more evident than the decrease in the airway wall area. Nevertheless, previous studies have suggested that the airway walls of subjects with COPD have a greater thickness than those of normal persons, and as the condition worsens, airway walls will gradually thicken, the lumen area will gradually decrease, and the wall area will gradually increase. ${ }^{26-28}$ This will result in a significant increase of airway wall area percentage, giving meaning to this parameter. On the other hand, Kosciuch et al ${ }^{18}$ found no significant correlations between airway wall thickness and spirometric parameters in subjects with asthma or COPD; however, in COPD, airway wall area percentage was positively correlated with airway resistance $(r=0.72$, $P<.001)$. Copley et $\mathrm{al}^{29}$ studied asymptomatic elderly subjects and reported that wall thickening was statistically more frequent in subjects who were $>75 \mathrm{y}$ old than in those $<55$ y of age.

Although the sample size in our study was relatively small, a control group was included, and measurements were made along a plane as perpendicular as possible to 


\section{HRCT FOR AsSESSING COPD SEVERITY}

Table 3. Correlations of Lung Function With Bronchial Size in Different Bronchus and COPD Grades

\begin{tabular}{|c|c|c|c|c|c|c|}
\hline $\begin{array}{c}\text { COPD Grade/Bronchi Location } \\
\text { and Bronchial Size }\end{array}$ & $\mathrm{FVC}$ & $\mathrm{FEV}_{1}, \%$ Predicted & $\mathrm{FEV}_{1} / \mathrm{FVC}$ & RV, \% Predicted & TLC, $\%$ Predicted & RV/TLC, \% Pr \\
\hline \multicolumn{7}{|l|}{ Control/RB1 } \\
\hline Inner area & -0.139 & -0.007 & 0.235 & -0.207 & -0.228 & -0.047 \\
\hline Airway wall area & -0.317 & -0.088 & 0.099 & -0.151 & -0.225 & 0.037 \\
\hline Airway wall area percentage & -0.191 & -0.032 & 0.393 & 0.08 & 0.067 & 0.16 \\
\hline \multicolumn{7}{|l|}{ Control/LB5 } \\
\hline Inner area & $0.469^{*}$ & 0.136 & 0.079 & -0.265 & -0.103 & -0.369 \\
\hline Airway wall area & 0.195 & 0.354 & -0.195 & 0.079 & 0.253 & -0.128 \\
\hline Airway wall area percentage & 0.087 & 0.243 & -0.028 & 0.446 & $0.508^{*}$ & 0.267 \\
\hline \multicolumn{7}{|l|}{ Control/RB6 } \\
\hline Inner area & 0.44 & 0.154 & 0.066 & 0.062 & 0.029 & 0.046 \\
\hline Airway wall area & 0.052 & -0.107 & $-0.591 * *$ & 0.284 & 0.191 & 0.311 \\
\hline Airway wall area percentage & -0.405 & -0.079 & 0.171 & 0.118 & 0.144 & 0.055 \\
\hline \multicolumn{7}{|l|}{ Grade I/RB1 } \\
\hline Inner area & 0.125 & 0.265 & 0.448 & 0.123 & 0.072 & 0.010 \\
\hline Airway wall area & 0.136 & 0.327 & 0.359 & 0.149 & 0.243 & -0.056 \\
\hline Airway wall area percentage & 0.097 & 0.126 & 0.19 & -0.331 & -0.152 & -0.190 \\
\hline \multicolumn{7}{|l|}{ Grade I/LB5 } \\
\hline Inner area & -0.343 & -0.428 & 0.254 & 0.271 & -0.046 & 0.328 \\
\hline Airway wall area & -0.178 & -0.38 & 0.237 & 0.244 & -0.055 & 0.315 \\
\hline Airway wall area percentage & 0.387 & 0.094 & -0.218 & -0.033 & 0.016 & 0.060 \\
\hline \multicolumn{7}{|l|}{ Grade I/RB6 } \\
\hline Inner area & 0.027 & -0.248 & 0.07 & -0.057 & -0.219 & 0.054 \\
\hline Airway wall area & -0.108 & -0.146 & 0.122 & 0.096 & -0.024 & 0.239 \\
\hline Airway wall area percentage & -0.393 & -0.362 & 0.197 & -0.087 & -0.206 & -0.140 \\
\hline \multicolumn{7}{|l|}{ Grade II/RB1 } \\
\hline Inner area & 0.099 & 0 & -0.288 & -0.017 & 0.28 & -0.379 \\
\hline Airway wall area & 0.063 & 0.112 & -0.245 & 0.046 & 0.4 & -0.329 \\
\hline Airway wall area percentage & -0.247 & -0.004 & 0.241 & -0.032 & -0.351 & 0.403 \\
\hline \multicolumn{7}{|l|}{ Grade II/LB5 } \\
\hline Inner area & 0.161 & 0.417 & -0.067 & -0.259 & -0.048 & -0.372 \\
\hline Airway wall area & 0.077 & 0.09 & -0.255 & -0.328 & -0.114 & $-0.506^{*}$ \\
\hline Airway wall area percentage & -0.05 & -0.393 & -0.235 & -0.124 & -0.085 & -0.225 \\
\hline \multicolumn{7}{|l|}{ Grade II/RB6 } \\
\hline Inner area & 0.098 & 0.124 & -0.043 & -0.029 & 0.202 & -0.053 \\
\hline Airway wall area & 0.405 & 0.221 & -0.447 & 0.021 & 0.247 & -0.264 \\
\hline Airway wall area percentage & -0.141 & 0.008 & 0.117 & -0.209 & -0.059 & -0.07 \\
\hline \multicolumn{7}{|l|}{ Grade III/RB1 } \\
\hline Inner area & 0.346 & -0.182 & 0.037 & -0.355 & -0.434 & -0.154 \\
\hline Airway wall area & 0.234 & -0.194 & 0.042 & $-0.474 *$ & $-0.523^{*}$ & -0.277 \\
\hline Airway wall area percentage & 0.27 & $-0.486^{*}$ & -0.299 & -0.402 & -0.417 & -0.199 \\
\hline \multicolumn{7}{|l|}{ Grade III/LB5 } \\
\hline Inner area & 0.289 & 0.018 & -0.113 & -0.399 & -0.343 & 0.018 \\
\hline Airway wall area & 0.306 & 0.1 & 0.047 & -0.426 & -0.362 & 0.076 \\
\hline Airway wall area percentage & $-0.490 *$ & 0.369 & 0.256 & 0.451 & 0.306 & 0.161 \\
\hline \multicolumn{7}{|l|}{ Grade III/RB6 } \\
\hline Inner area & 0.448 & 0.081 & -0.173 & -0.11 & 0.033 & -0.307 \\
\hline Airway wall area & $0.519^{*}$ & -0.061 & -0.186 & -0.155 & 0.003 & -0.356 \\
\hline Airway wall area percentage & -0.175 & 0.125 & 0.054 & 0.22 & 0.207 & 0.092 \\
\hline \multicolumn{7}{|l|}{ Grade IV/RB1 } \\
\hline Inner area & 0.082 & -0.231 & 0.02 & -0.044 & 0.061 & -0.092 \\
\hline Airway wall area & 0.029 & -0.152 & 0.141 & 0.099 & 0.19 & 0.013 \\
\hline Airway wall area percentage & 0.35 & -0.075 & 0.191 & -0.186 & -0.035 & -0.381 \\
\hline
\end{tabular}


Table 3. Continued.

\begin{tabular}{|c|c|c|c|c|c|c|}
\hline $\begin{array}{c}\text { COPD Grade/Bronchi Location } \\
\text { and Bronchial Size }\end{array}$ & $\mathrm{FVC}$ & $\mathrm{FEV}_{1}, \%$ Predicted & $\mathrm{FEV}_{1} / \mathrm{FVC}$ & RV, \% Predicted & TLC, $\%$ Predicted & RV/TLC, \% Predicted \\
\hline \multicolumn{7}{|l|}{ Grade IV/LB5 } \\
\hline Inner area & 0.14 & -0.242 & 0.39 & 0.359 & 0.293 & 0.442 \\
\hline Airway wall area & 0.161 & 0.08 & 0.36 & 0.419 & 0.231 & 0.186 \\
\hline Airway wall area percentage & -0.057 & 0.458 & -0.088 & -0.13 & -0.315 & -0.461 \\
\hline \multicolumn{7}{|l|}{ Grade IV/RB6 } \\
\hline Inner area & -0.124 & -0.074 & -0.071 & 0.119 & 0.197 & -0.117 \\
\hline Airway wall area & -0.084 & -0.003 & 0.121 & 0.249 & 0.22 & 0.029 \\
\hline Airway wall area percentage & 0.149 & 0.343 & -0.107 & -0.209 & -0.166 & -0.482 \\
\hline \multicolumn{7}{|c|}{$\begin{array}{l}\text { Data are presented as coefficient of correlation with adjustment for body mas index for given COPD grade. *, } P<.05 ; * *, P<.001 \text {; significant correlation. } \\
\text { RV }=\text { residual volume } \\
\text { TLC = predicted total lung capacity } \\
\text { RB1 = apical segment of the right upper lobe bronchi } \\
\text { RB6 = posterior segment of the right lower lobe } \\
\text { LB5 = lower lingual segment of upper left lobe bronchi }\end{array}$} \\
\hline
\end{tabular}

the long axis of the airway. In addition, in contrast to manual or semi-automatic measurements, the relatively mature Vida fully automated measurement software, which has been validated in other studies, ${ }^{30-32}$ was used. We thus believe that discrepancies between the results of other studies and our results are not just a variation between the methods but reflect the real airway status. It appears that airway remodeling caused by chronic inflammation and fibrosis appearing at late stages will cause the airway lumen to shrink, and the airway wall will become correspondingly thinner. However, this conclusion must be verified by pathological examination.

Past studies of quantitative measurements of bronchial size in subjects with asthma and COPD have suggested a correlation between bronchial size and pulmonary function, ${ }^{33,34}$ although this depends on the parameters examined and has not been shown in some studies. ${ }^{18}$ The current study also found correlations between the airway size of subjects with COPD and pulmonary function, including RB1 in subjects with grade IV COPD and pulmonary function indices. However, at an advanced stage (GOLD grade IV), changes in RB6 and LB5 not were observed. Although we cannot know for certain, we believe that these results can be explained as follows. Bronchial plasticity was not evident in grade I subjects, whereas in grade II subjects, bronchial plasticity began to occur, and there simultaneously existed inflammatory edema. Although grade III and IV subjects have more severe disease, their bronchial plasticity was evident, a high degree of fibrosis was present, and the fibrosis caused even greater contraction of the bronchial wall. As for whether different grades have effects in different locations, clinical experience indicates that inflammation significantly changes the parallel routing of the bronchi to a greater degree, and RB1 is vertical or oblique. Because of this, this bronchus (RB1) may be influenced even more significantly in patients with a higher COPD grade. Plasticity should be even more evident in the case of RB6 and LB5, and inflammatory edema of the bronchial wall might not be very severe.

Among airway inner area, airway wall area, and airway wall area percentage values, inner area and airway wall area percentage had relatively high correlations with pulmonary function. Inner area was positively correlated with FVC and negatively correlated with RV/TLC. This indicates that the smaller the airway lumen, the more pulmonary ventilation and small-airway function will deteriorate, and RV will worsen even more. Airway wall area percentage was negatively correlated with $\mathrm{FVC}, \mathrm{FEV}_{1}$, and $\mathrm{FEV}_{1} / \mathrm{FVC}$ and positively correlated with RV/TLC, which indicates that the larger the airway wall area and the smaller the airway lumen, the greater the degree of airflow obstruction. This further indicates that bronchial changes not only occur in peripheral small airways, but also affect central, relatively large airways. Previous studies have reported a negative correlation between quantitative airway wall thickness determined by CT and pulmonary function, a negative correlation between airway wall area percentage and percent-of-predicted $\mathrm{FEV}_{1}$ and $\mathrm{FEV}_{1} / \mathrm{FVC}$, and a positive correlation between airway wall area percentage and RV/TLC. ${ }^{27,35}$ Patel et $\mathrm{al}^{36}$ have suggested that the best correlation exists between airway wall thickness and RV/TLC.

It should be noted that although the inner areas for subjects with COPD and controls were not significantly different, the data in Table 2 appear to show a significant correlation between inner area and FVC for all 3 segments examined. This is because the subjects included for the analysis in the tables are different. The correlation noted between inner area and FVC was probably caused by grade (Table 1), and when all of the subjects were pooled (Table $3)$, the correlations differed. 
There are certain limitations, as well as strengths of the current study. The numbers of subjects with the different grades of COPD were relatively small. The study, however, evaluated a sufficient number of bronchi to select optimal sites for diagnosis, and this study focused on airway parameters, whereas prior similar studies focused on emphysema. Given the pathogenesis of COPD, detailed airway measurement probably provides more meaningful information. It would be ideal if it were possible to measure all 18 bronchopulmonary segments; however, the work involved in this would be beyond the scope of most researchers. RB1 represents the upper lobe and has been used in most prior studies, and because RB6 and LB5 represent the largest lobes of the right and left lungs, analysis of them makes it relatively easy to assess changes. We believe that assessment of these 3 segments is representative of the condition of the lobes they represent. It may have been beneficial to analyze emphysema and airway size together; however, other studies have examined airway dimensions and emphysema, and the purpose of this study was to focus on airway size and simplify the analysis. Both inspiratory and expiratory studies were performed, but only inspiratory views were included in this study. This was because in expiratory views, the airway was very constricted during the expiratory phase, especially due to collapse of the posterior wall, so the software could not accurately assess the condition of the airway. Coupled inspiratory-expiratory studies, however, have proven to be informative in some reports, because assessment of changes in inspiration-expiration is important for correlating bronchial size with PFT. ${ }^{35-37}$ TLC and RV were measured using body plethysmography, and results obtained with this method may be discrepant with those of other methods, such as helium dilution. COPD affects the airway wall and lung parenchyma to varying degrees, and air trapping and air wall thickening are associated. The results showed no correlation between the degree of bronchial obstruction and air trapping. Air trapping is more related to lung parenchyma changes, and the aim of the present study is to evaluate the airway wall changes among different degrees of COPD. For this reason, we did not analyze parenchyma changes.

\section{Conclusions}

The results of this study suggest that airway parameters in different COPD grades have no uniform tendency of correlation with PFT, but some HRCT parameters are correlated to some PFT parameters. This may allow the use of HRCT as an easier and more objective assessment of patients with COPD, as compared with PFT, in routine clinical practice. Our results indicated that in COPD grade II, RV/TLC was negatively correlated with airway wall area in LB5. In COPD grade III, FVC was negatively corre- lated with airway wall area percentage in LB5 but positively correlated with airway wall area in RB6; percentof-predicted $\mathrm{FEV}_{1}$ was negatively correlated with airway wall area percentage in RB1; RV and TLC were negatively correlated with airway wall area in RB1. A complete HRCT assessment system for patients with different grades of COPD could be developed after more studies and more detailed analysis of this topic.

\section{REFERENCES}

1. Vestbo J, Hurd SS, Agustí AG, Jones PW, Vogelmeier C, Anzueto A, et al. Global strategy for the diagnosis, management, and prevention of chronic obstructive pulmonary disease: GOLD executive summary. Am J Respir Crit Care Med 2013;187(4):347-365.

2. Rennard SI, Vestbo J. The many "small COPDs": COPD should be an orphan disease. Chest 2008;134(3):623-627.

3. Hogg JC, McDonough JE, Sanchez PG, Cooper JD, Coxson HO, Elliott WM, et al. Micro-computed tomography measurements of peripheral lung pathology in chronic obstructive pulmonary disease. Proc Am Thorac Soc 2009;6(6):546-549.

4. McDonough JE, Yuan R, Suzuki M, Seyednejad N, Elliott WM, Sanchez PG, et al. Small-airway obstruction and emphysema in chronic obstructive pulmonary disease. N Engl J Med 2011;365(17): 1567-1575.

5. Kosciuch J, Krenke R, Gorska K, Zukowska M, MaskeyWarzechowska M, Chazan R. Airway dimensions in asthma and COPD in high resolution computed tomography: can we see the difference? Respir Care 2013;58(8):1335-1342.

6. Amirav I, Kramer SS, Grunstein MM, Hoffman EA. Assessment of methacholine-induced airway constriction by ultrafast high-resolution computed tomography. Appl Physiol 1993;75(5):2239-2250.

7. Chen H, Chen RC, Guan YB, Li W, Liu Q, Zeng QS. Correlation of pulmonary function indexes determined by low-dose MDCT with spirometric pulmonary function tests in subjects with chronic obstructive pulmonary disease. AJR Am J Roentgenol 2014;202(4): 711-718.

8. Agusti A, Calverley PM, Celli B, Coxson HO, Edwards LD, Lomas DA, et al. Characterisation of COPD heterogeneity in the ECLIPSE cohort. Respir Res 2010;11:122.

9. Kim V, Han MK, Vance GB, Make BJ, Newell JD, Hokanson JE, et al. The chronic bronchitic phenotype of COPD: an analysis of the COPDGene Study. Chest 2011;140(3):626-633.

10. Capraz F, Kunter E, Cermik H, Ilvan A, Pocan S. The effect of inhaled budesonide and formoterol on bronchial remodeling and HRCT features in young asthmatics. Lung 2007;185(2):89-96.

11. Deveci F, Murat A, Turgut T, Altuntaş E, Muz MH. Airway wall thickness in subjects with COPD and healthy current smokers and healthy non-smokers: assessment with high resolution computed tomographic scanning. Respiration 2004;71(6):602-610.

12. Pauls S, Gulkin D, Feuerlein S, Muche R, Krüger S, Schmidt SA, et al. Assessment of COPD severity by computed tomography: correlation with lung functional testing. Clin Imaging 2010;34(3):172178.

13. Lee HJ, Seo JB, Chae EJ, Kim N, Lee CW, Oh YM, Lee SD. Tracheal morphology and collapse in COPD: correlation with CT indices and pulmonary function test. Eur J Radiol 2011;80(3):e531e535.

14. Yasunaga K, Chérot-Kornobis N, Edmé JL, Sobaszek A, Boulenguez C, Duhamel A, et al. Emphysema in asymptomatic smokers: quantitative CT evaluation in correlation with pulmonary function tests. Diagn Interv Imaging 2013;94(6):609-617. 


\section{HRCT FOR ASSESSING COPD SEVERITY}

15. Guan Y, Xia Y, Fan L, Liu SY, Yu H, Li B, et al. Quantitative assessment of pulmonary perfusion using dynamic contrast-enhanced $\mathrm{CT}$ in subjects with chronic obstructive pulmonary disease: correlations with pulmonary function test and CT volumetric parameters. Acta Radiol 2015;56(5):573-580.

16. Kauczor HU, Wielpütz MO, Owsijewitsch M, Ley-Zaporozhan J. Computed tomographic imaging of the airways in COPD and asthma. J Thorac Imaging 2011;26(4):290-300.

17. Hackx M, Bankier AA, Gevenois PA. Chronic obstructive pulmonary disease: CT quantification of airways disease. Radiology 2012; 265(1):34-48.

18. Kosciuch J, Krenke R, Gorska K, Zukowska M, MaskeyWarzechowska M, Chazan R. Relationship between airway wall thickness assessed by high-resolution computed tomography and lung function in subjects with asthma and chronic obstructive pulmonary disease. J Physiol Pharmacol 2009;60(Suppl 5):71-76.

19. Nakano Y, Muro S, Sakai H, Hirai T, Chin K, Tsukino M, et al. Computed tomographic measurements of airway dimensions and emphysema in smokers: correlation with lung function. Am J Respir Crit Care Med 2000;162(3 Pt 1):1102-1108.

20. Nakano Y, Wong JC, de Jong PA, Buzatu L, Nagao T, Coxson HO, et al. The prediction of small airway dimensions using computed tomography. Am J Respir Crit Care Med 2005;171(2):142-146.

21. Matsuoka S, Yamashiro T, Washko GR, Kurihara Y, Nakajima Y, Hatabu H. Quantitative CT assess of chronic obstructive pulmonary disease. Radiographics 2010;30(1):55-66.

22. Matsuoka S, Kurihara Y, Yagihashi K, Nakajima Y. Quantitative assessment of peripheral airway obstruction on paired expiratory/ inspiratory thin-section computed tomography in chronic obstructive pulmonary disease with emphysema. J Comput Assist Tomogr 2007; 31(3):384-389.

23. Mets OM, Murphy K, Zanen P, Gietema HA, Lammers JW, van Ginneken B, et al. The relationship between lung function impairment and quantitative computed tomography in chronic obstructive pulmonary disease. Eur Radiol 2012;22(1):120-128.

24. Rabe KF, Hurd S, Anzueto A, Barnes PJ, Buist SA, Calverley P, et al. Global strategy for the diagnosis, management, and prevention of chronic obstructive pulmonary disease: GOLD executive summary. Am J Respir Crit Care Med 2007;176(6):532-555.

25. Lederlin M, Laurent F, Dromer C, Cochet H, Berger P, Montaudon M. Mean bronchial wall attenuation value in chronic obstructive pulmonary disease: comparison with standard bronchial parameters and correlation with function. AJR Am J Roentgenol 2012;198(4): 800-808.

26. Achenbach T, Weinheimer O, Biedermann A, Schmitt S, Freudenstein D, Goutham E, et al. MDCT assessment of airway wall thick- ness in COPD subjects using a new method: correlations with pulmonary function tests. Eur Radiol 2008;18(12):2731-2738.

27. Mair G, Maclay J, Miller JJ, McAllister D, Connell M, Murchison JT, MacNee W. Airway dimensions in COPD: relationships with clinical variables. Respir Med 2010;104(11):1683-1690.

28. Johannessen A, Skorge TD, Bottai M, Grydeland TB, Nilsen RM, Coxson $\mathrm{H}$, et al. Mortality by level of emphysema and airway wall thickness. Am J Respir Crit Care Med 2013;187(6):602-608.

29. Copley SJ, Wells AU, Hawtin KE, Gibson DJ, Hodson JM, Jacques AE, Hansell DM. Lung morphology in the elderly: comparative CT study of subjects over 75 years old versus those under 55 years old. Radiology 2009;251(2):566-573

30. Van Tho N, Wada H, Ogawa E, Nakano Y. Recent findings in chronic obstructive pulmonary disease by using quantitative computed tomography. Respir Investig 2012;50(3):78-87.

31. Hartley RA, Barker BL, Newby C, Pakkal M, Baldi S, Kajekar R, et al. Relationship between lung function and quantitative computed tomographic parameters of airway remodeling, air trapping, and emphysema in subjects with asthma and chronic obstructive pulmonary disease: a single-center study. J Allergy Clin Immunol 2016;137(5): 1413-1422.e12.

32. Gupta S, Hartley R, Khan UT, Singapuri A, Hargadon B, Monteiro W, et al. Quantitative computed tomography-derived clusters: redefining airway remodeling in asthmatic subjects. J Allergy Clin Immunol 2014;133(3):729-738.e18.

33. Grydeland TB, Thorsen E, Dirksen A, Jensen R, Coxson HO, Pillai SG, et al. Quantitative CT measures of emphysema and airway wall thickness are related to D(L)CO. Respir Med 2011;105(3):343-351.

34. Mohamed Hoesein FA, de Jong PA, Lammers JW, Mali WP, Mets OM, Schmidt M, et al. Contribution of CT quantified emphysema, air trapping and airway wall thickness on pulmonary function in male smokers with and without COPD. COPD 2014;11(5):503-509.

35. Kim SS, Seo JB, Lee HY, Nevrekar DV, Forssen AV, Crapo JD, et al. Chronic obstructive pulmonary disease: lobe-based visual assess of volumetric CT by using standard images-comparison with quantitative $\mathrm{CT}$ and pulmonary function test in the COPDGene study. Radiology 2013;266(2):626-635.

36. Patel BD, Coxson HO, Pillai SG, Agustí AG, Calverley PM, Donner $\mathrm{CF}$, et al. Airway wall thickening and emphysema show independent familial aggregation in chronic obstructive pulmonary disease. Am J Respir Crit Care Med 2008;178(5):500-505.

37. Brennan D, Schubert L, Diot Q, Castillo R, Castillo E, Guerrero T, et al. Clinical validation of 4-dimensional computed tomography ventilation with pulmonary function test data. Int J Radiat Oncol Biol Phys 2015;92(2):423-429. 